\title{
BREVE CARACTERIZACIÓN HISTÓRICA DE LA REGIÓN METROPOLITANA DE BUENOS AIRES
}

\author{
Tomás Calello \\ Instituto del Conurbano, Universidad Nacional de General Sarmiento San Miguel, Buenos Aires
}

\begin{abstract}
Resumen: En este artículo se delinea suscintamente la conformación y el desarrollo histórico de la Región Metropolitana de Buenos Aires. Con ese fin se analizan sus modificaciones territoriales en relación a las principales dimensiones económicas, sociales y políticas presentes en cada período considerado. Las mismas dan cuenta de la pérdida de competitividad de la región en su conjunto en relación a su contexto nacional e internacional.

Palabras clave: metropolización en Latinoamérica; Región Metropolitana de Buenos Aires.
\end{abstract}

I a Región Metropolitana de Buenos Aires (RMBA) es actualmente una de las cinco megaciudades de Latinoamérica. Con un número de habitantes que alcanza, en el año 2000, al 37,3\% de la población total de Argentina. En una superficie que abarca sólo el 0,4\% del territorio nacional, concentra asimismo las principales actividades económicas, políticas y culturales.

En la conformación histórica de su territorio pueden distinguirse cuatro etapas. Las mismas serán diferenciadas de acuerdo a la inserción de la RMBA en la economía nacional y mundial, los sectores y clases sociales dominantes y su distribución en el espacio; como así también, las características territoriales en cada período considerado y su relación con la población.

La primera etapa que podemos denominar de formación comprende el periodo 1865-1930, la segunda etapa, de crecimiento, abarca desde 1930 hasta 1970, la tercera, de estabilización-transición tiene lugar entre 1970 y 1990, y la última etapa, caracterizada por la inserción global de la región, abarca desde el año 1990 hasta la actualidad.

\section{ETAPA DE FORMACIÓN DE LA RMBA (1865-1930)}

A fines del siglo XIX y principios del XX el crecimiento de la ciudad fue impulsado por la demanda de servicios, transporte y mano de obra, en particular inmigrante, re- queridos por el modelo económico agroexportador y que tuvo como fundamento la producción agrícolo-ganadera, asentada en la Pampa Húmeda, con destino a Europa, particularmente a Inglaterra.

Desde la formación del estado nacional se había consolidado la hegemonía de la clase terrateniente conocida como "oligarquía". La naturaleza rentista de esta clase le permitió asentarse en Buenos Aires, federalizada en el año 1880. El predominio del modelo agroexportador dio lugar a una etapa de progreso económico basado en el dominio de una élite económica, política y cultural cuyos logros en esos campos otorgaron al período - que se caracterizó a su vez por la importancia que adquirieron las distintas oleadas inmigratorias, particularmente las originadas en Europa meridional - una singularidad histórica.

Los inmigrantes debieron establecerse mayoritariamente en conventillos, hoteles de inquilinato y bodegones situados en la Capital Federal y en menor medida colonizando zonas de la región mesopotámica. El crecimiento de las casas de inquilinato fue de una gran envergadura. En el año 1881 existían 1.821 casas habitadas por 65.260 personas que representaban el $21,6 \%$ de la población porteña. En 1904 el número de inquilinatos era de 2.462 y el números de moradores alcanzaba a 138.188 , pero disminuyendo el porcentaje relativo de la población de la ciudad al $14,5 \%$. Esta tendencia decreciente se mantuvo 
y en 1919 todavía el 8,9\% de los porteños vivían en casas de inquilinato.

La precaria situación habitacional y las condiciones que los arrendatarios imponían a los inquilinos dieron lugar a una de las huelgas más importantes de la época en el año 1907 (Suriano, 1983). La Capital Federal concentraba asimismo un creciente número de actividades artesanales que se realizaban en pequeños establecimientos fabriles.

Desde la década de los años 20 los hijos de los inmigrantes serán integrados en las actividades de servicios y profesionales impulsadas por el desarrollo del puerto de Buenos Aires, convertido por entonces en cabecera ferroviaria y centro financiero. El Ferrocarril del Oeste vinculaba las áreas productoras con el puerto a través de una extensión de aproximadamente $150 \mathrm{~km}$ configurando la aparición de un eje radial de desarrollo urbano. Entre los años 1880 y 1914, el rápido crecimiento que tuvo lugar en la región como consecuencia de las exportaciones agrícolo-ganaderas, demandó la construcción de obras de infraestructura como la electrificación de la red tranviaria, obras de salubridad, el alumbrado público, tendido de vías férreas, la construcción del puerto, entre otros, cuya propiedad pertenecía mayoritariamente a compañías de orígen británico y francés. El puerto y los frigoríficos tuvieron un papel central en la concentración del aparato público.

La clase media será integrada al modelo agroexportador mediante importantes reformas al sistema político, entre las que se destacó la ley Sáenz Peña de 1912, obteniendo una creciente participación en las rentas generadas por las exportaciones de materias primas.

Hacia 1869, Buenos Aires contaba con una población de 187.000 habitantes (el 13\% de la población del país) en una superficie menor a los $100 \mathrm{~km}^{2}$. En al año 1914, el $25,8 \%$ que la región representaba en el total de la población del país estaba integrada en un $20 \%$ por la Capital Federal y apenas un $5,8 \%$ por los partidos del Conurbano, contando con casi 2.000.000 de habitantes. El área que ocupaba la región había crecido 16 veces desde 1969. Hacia fines del período considerado, Buenos Aires era la mayor aglomeración de América Latina y la séptima en el mundo abarcando un área de $390 \mathrm{~km}^{2}$.

La crisis de la economía mundial, que se desata con la caída de la bolsa de Wall Street, afectó la división internacional del trabajo que había reservado al país la exportación de materias primas y la importación de manufacturas. Asimismo, generó las condiciones para modificar la dependencia de la RMBA en relación a las zonas de Argentina donde se asentaba la producción agrícolo-ganadera.

\section{ETAPA DE CRECIMIENTO (1930-1970)}

Teniendo como eje principal al puerto de Buenos Aires y a la ciudad que lo circunda, la RMBA trascendió desde la década de los 30 sus límites originales y adquirió un desarrollo específico y autónomo. La región comenzará a perfilarse como el principal centro productivo del país.

El desarrollo del proceso sustitutivo de importaciones, particularmente de bienes terminados de consumo duradero y bienes de capital simple como textiles, alimenticios, químicos y mecánicos, dará lugar al establecimiento de un importante número de pequeñas y medianas empresas situadas en la Capital Federal y los partidos colindantes que concentraron la ubicación de la clase obrera.

En principio como respuesta casi espontánea ante la crisis económica mundial y la restricción de los mercados durante la década de los 30 y luego como resultado de una creciente intervención estatal, la expansión del capital nacional se irá plasmando en una configuración urbana que predominará hasta la década de los 70. Asimismo tienen lugar durante aquella década inversiones extranjeras directas en los rubros de la alimentación, textil, eléctrico y caucho. El desarrollo y consolidación del llamado primer cordón industrial que constituirá el Conurbano Bonaerense atrajo una población migrante proveniente del interior del país y que será la base de los nuevos movimientos sociales y políticos de la época. Hacia el año 1935, la producción industrial superó a la agrícola.

La nacionalización de los ferrocarriles, transportes, teléfono y telégrafos, gas, electricidad, banco central, puertos y empresas de seguros, junto a la nacionalización de los servicios públicos y los recursos naturales permitió la consolidación, durante la década de los 40 , de un régimen de acumulación de capital basado en la expansión de la burguesía industrial nacional y del consumo interno que cimentó la alianza entre el capital y el trabajo. Los sindicatos y sus reivindicaciones sociales fueron, en gran medida, integrados en el discurso y las políticas estatales que favorecieron importantes mejoras en las condiciones laborales de los asalariados.

El tipo de sustitución de importaciones, anterior al bienio 1948-1950, estuvo centrado en el desarrollo de las industrias textil y liviana, en detrimento de las industrias de bienes intermedios y de capital (Lombardo, 1999). La abundancia de divisas provenientes del sector externo 
permitió la importación de los bienes de capital e intermedios, necesarios para el desenvolvimiento de la industria, como así también, la expansión del crédito para la vivienda y el crecimiento de los servicios. Ello se vió favorecido mediante la creación del IAPI (Instituto Argentino de Promoción Industrial), institución encargada de transferir la renta agrícola al sector industrial, afectando negativamente los intereses de la oligarquía tradicional.

En los primeros años de la década de los 50, comienza el agotamiento de este modo de acumulación que habría de culminar con la alianza de los grupos sociales que lo sustentaron y dando lugar a una crisis de hegemonía que se prolongará por varias décadas. Las políticas recesivas, que comenzaron a aplicarse desde 1953, junto a la pérdida de apoyo al gobierno peronista del ejército, la iglesia y los partidos políticos, afectaron a las relaciones tejidas entre el estado, las organizaciones patronales y los sindicatos que tenían como sustento la expansión del consumo.

La restricción de las exportaciones argentinas a los mercados europeos y la necesidad de importar los insumos no producidos en el país generaron los cuellos de botella del balance comercial característicos del período. A ello se agregaba la crisis de las políticas distributivas de ingresos al afectar las tasas de ganancia. Las industrias que se habían expandido, como las que suministraban bienes para el consumo masivo, se estancaron, mientras que las transformaciones en la infraestructura (red vial y caminera, energía instalada, etc) agravaron la crisis al no poder satisfacer las necesidades de la industria.

Esta situación condujo a una reconsideración de la política de inversiones extranjeras, prestando mayor atención desde 1953, a los establecimientos grandes dedicados a la industria pesada y semipesada como los que se instalarán en el país durante la presidencia de Arturo Frondizi (1958-1962). Las inversiones extranjeras alcanzan durante ese período los 500 millones de dólares, dando lugar a una segunda fase del modelo sustitutivo de importaciones encabezada por los sectores metal-mecánico y petroquímico. A su vez, indujo modificaciones de las relaciones existentes hasta entonces entre los sectores agrario e industrial, favoreciendo, mediante la devaluación de la moneda nacional, a las fracciones exportadoras y fortaleciendo, también, los aspectos burocráticos y autoritarios del estado en relación a los partidos políticos y los sindicatos.

Hasta la década de los 40, la segregación social, es decir, la distribución espacial de los distintos grupos y clases sociales se encontró definida en mayor medida por las diferencias entre los sectores urbanos (norte, oeste y las dos ramas del sector sud) que por aquéllas definidas por el sentido de los ejes radiales (Torres, 1993).

Para el año 1938, Nicolás Besio Moreno adjudicaba a la región que comprendía a la Capital Federal y el Gran Buenos Aires una población de 3.600 .000 habitantes, distribuídos en una extensión de $1.190 \mathrm{~km}^{2}$. Tomando como criterio la densidad poblacional, establecía para sus límites un área de aproximadamente $50 \mathrm{~km}^{2}$ desde el centro de la Capital. El área llegaba hasta las ciudades de Berazategui, Florencio Varela, Burzaco y Monte Grande por el sur, Tapiales, Tablada, Morón y Merlo por el oeste, Bella Vista, San Miguel y José C. Paz al noroeste y las de Tigre y Las Conchas por el norte. Los partidos aledaños a la Capital Federal urbanizados completamente eran, por esa época, Avellaneda, Lomas de Zamora, San Martín, Vicente López, San isidro y San Fernando. Solamente urbanizados en parte se encontraban Quilmes, Florencio Varela, Almirante Brown, Esteban Echeverría, Matanza, Merlo, Seis de Septiembre, Sarmiento y Las Conchas (Caride, 1999) A su vez Bonifacio del Carril estimaba, hacia 1944, una superficie para el Gran Buenos Aires (GBA) bastante inferior a la atribuída por Besio Moreno pero considerando sólo a la Capital Federal y los Partidos de Avellaneda, Lomas de Zamora, Vicente López, San Isidro, San Martín, Seis de Septiembre, parte de Las Conchas, parte de Almirante Brown, parte de Quilmes y parte de La Matanza en la Provincia de Buenos Aires (Caride, 1999).

A comienzos de la década de los 40 , la forma de tenencia predominante en el mercado residencial era el alquiler, mientras que en las dos décadas anteriores la más importante contribución a la tipología residencial fueron las casas de departamentos dirigidas a las clases medias. La ley de alquileres de 1943, congeló el valor de los mismos y generó efectos contradictorios al restringir su mercado y favorecer de manera indirecta el auge de otras formas de acceso a la propiedad.

Un fenómeno urbano significativo que se comienza a consolidar durante este período, es el de las "villas miseria", como resultado de la expansión urbana, preferentemente a lo largo del primer cordón industrial, y, las migraciones internas. Generalmente ubicadas en terrenos fiscales, como los pertenecientes a puertos y ferrocarriles, o el anillo que sigue las cuencas inundables de los ríos Matanza-Riachuelo y Reconquista, serán construídas por los sectores que quedaron marginados del mercado residencial formal (Torres, 1993). 
Hasta bien entrada la década de los 70 , las "villas miseria" constituyeron la forma precaria predominante de ocupación del suelo y uno de los mayores símbolos del desarraigo popular.

En el IV Censo General de la Nación realizado a principios del año 1947, el Gran Buenos Aires (GBA) fué reconocido como unidad censal que ameritaba una consideración específica independiente del resto de los partidos de la Provincia de Buenos Aires e incluía también a la Capital Federal.

La región del GBA contaba con 4.700 .000 habitantes que constituían el $30 \%$ de la población del país, de las cuáles un tercio residían en el conurbano bonaerense Los 17 partidos vecinos a Buenos Aires considerados fueron Almirante Brown, Avellaneda, Cuatro de Junio (Lanús), Esteban Echeverría, Florencio Varela, General San Martín, General Sarmiento, La Matanza, Las Conchas (Tigre), Lomas de Zamora, Merlo, Moreno, Morón, Quilmes, San Fernando, San Isidro y Vicente López (Caride, 1999). Desde entonces la población de la Capital Federal, que rondaba los tres millones de habitantes, practicamente se estancó y tendió a decrecer en términos absolutos. Pero no será sino hasta fines de los años 50 que la conurbación superará en número de habitantes a la Capital Federal.

Las ideas que guiaron el desarrollo urbano durante el período 1945-1955, consideraban que las fuerzas principales se basaban en la propiedad privada inmobiliaria y la forma privada de producir la ciudad, bajo el control, la coordinación, la financiación y el apoyo del estado (Lombardo, 1999). La concepción que las guiaba estaba conformada por el paradigma racionalista, basado en una consideración funcional del espacio y la ciudad y en la necesidad de su planificación. A ello se agregaba la consideración de la vivienda individual en propiedad para el grupo familiar, agrupada en forma vertical y horizontal, como la base del orden espacial.

El fomento a la acumulación estaba dado fundamentalmente por la extracción de la renta del suelo, la obtención de la ganancia de las empresas constructoras y las empresas asociadas a la construcción en la sustitución de importaciones. Estas ideas fueron escritas y formuladas por etapas en el Primer Plan de Gobierno (1947-1951) y en el Segundo Plan Quinquenal (1953).

Sin embargo recién en el Segundo Plan Quinquenal se estipula la realización de planes reguladores que quedan interrumpidos con el golpe de estado de 1955. La distribución del suelo de las áreas en crecimiento, hasta el año 1960, no fue consecuencia de la planificación sino del desarrollo del mercado inmobiliario (Lombardo, 1999).

El proceso histórico de urbanización dió por resultado una estructura urbana orientada geográficamente a lo largo de los ejes principales de transporte, constituídos hasta 1930 por las vías férreas, complementados por las vías de transporte automotor y el lento proceso de vinculación vial intersticial, es decir, entre los ejes principales que tienen una dirección desde el centro de Buenos Aires hacia la periferia, situación que aún hoy se observa.

Esta configuración tentacular presentaba áreas de diversa densidad de población, de infraestructura urbana y de dotación de servicios. Todas estas densidades tendían a decrecer desde los ejes centrales hacia los grandes espacios intersticiales entre estos ejes.

A partir de 1940, la propiedad en alquiler pierde importancia en relación al incremento de la propiedad residencial y a las viviendas populares, asentadas sobre terrenos obtenidos por medio de loteos económicos.

Las formas que adquirió el proceso de urbanización durante la vigencia del modelo sustitutivo de importaciones tuvieron como uno de los pilares fundamentales el apoyo brindado por el estado al desarrollo del transporte y la vivienda. El subsidio al precio de las tarifas de transporte facilitaba el desplazamiento masivo de los trabajadores, en un proceso de suburbanización creciente, que complementaba las facilidades para adquirir y construir viviendas en zonas cada vez más alejadas de la ciudad capital y con escasas dotaciones de servicios e infraestructuras. El auge de los loteos económicos permitió a los sectores populares obtener terrenos a bajo costo y sometidos a una fuerte especulación inmobiliaria, que privilegiaba la discontinuidad del trazado urbano, de acuerdo a requisitos previos de valorización. Al tiempo insumido por los desplazamientos se agregaba, debido a un régimen de salarios que no incorporaba a los servicios urbanos de alta demanda social, la necesidad de la autoconstrucciòn, y en menor medida, la compra de viviendas prefabricadas. El estado intervenía atenuando la expoliación del trabajo y garantizando los requisitos mínimos para su reproducción.

Desde 1955, se acentuó el predominio del mercado y su influencia en la urbanización de la región facilitó el desarrollo de un segundo anillo en el GBA.

Hasta la década de los 80 fueron realizados un conjunto de planes urbanos y estudios técnicos de importancia, entre ellos el "Esquema Director - Año 2000" (CONADE), que permanecieron casi invariablemente sin ejecutarse, debido a los intereses contrapuestos de las diversas 
jurisdicciones que formaban parte de la región y porque no llegaron a ser considerados por la opinión pública y el discurso político.

Desde 1960, se produjeron modificaciones de importancia en los usos legales del suelo y en el proceso de suburbanización. Entre los primeros se contaron los intentos de regular el proceso de urbanización por medio de la ley 8.914 de 1977. Sin embargo estas normas debieron enfrentar numerosos obstáculos y su carencia de legitimidad.

Desde mediados de la década de los 60 , se produce la disminución progresiva del subsidio al transporte y su incidencia en el proceso de suburbanización. Durante el período considerado, la tasa de crecimiento urbano de la RMBA fue del $2,5 \%$, superior a la nacional $(1,8 \%)$, sin embargo, el crecimiento de la población pasa de 6.700 .000 habitantes en 1960, a 8.500.000 en 1970, lo que representó un crecimiento de solo el 2,1\%.

A ello se agregaba la merma de la contribución en ese proceso de los loteamientos económicos junto a la caída de la tasa de crecimiento del Gran Buenos Aires y el deterioro de las condiciones sociohabitacionales. En consonancia, se duplica el número de habitantes de las "villas miseria" que pasan del 5\% en 1960, al 11,24\% en 1970 (Torres, 1993). A su vez tuvo lugar una tendencia creciente a la suburbanización residencial, facilitada por la habilitación del Acceso Norte y la Autopista Panamericana permitiendo, a los sectores de mayores ingresos, una vinculación más directa con la periferia urbana y que contrastaba con el deficiente servicio del transporte público (Torres, 1993; Cicolella, 1999).

Durante la etapa sustitutiva de importaciones, el 60\% de la industria nacional llega a concentrarse en la RMBA, que se convirtió en el principal mercado de consumo del país, incluso para productos provenientes de otras regiones como algodón, té, arroz, yerba mate, vino, frutas, gas, petróleo, etc.

\section{ETAPA DE ESTABILIZACIÓN Y TRANSICIÓN (1970-1990)}

Este periodo se caracterizó por el agotamiento del modelo sustitutivo de importaciones, la concentración de los capitales, comandados por el financiero, y, la emergencia de actividades terciarias improductivas y cuentapropistas que tienen lugar en la RMBA.

La crisis del modelo industrializador endógeno y del estado de bienestar, hacia el año 1975, confinó a vastos sectores de la población fuera de los mercados laborales y de los servicios e infraestructuras urbanas mínimos. Durante el periodo 1976-1983, las políticas urbanas implementadas por el gobierno militar influenciaron drasticamente el sentido de las transformaciones sociespaciales que afectaron a la región, mediante las relocalizaciones industriales, la creación del cordón ecológico, la construcción de autopistas junto a las expropiaciones de bienes, la liberación general de alquileres y la erradicación de villas miseria de la Capital Federal y su posterior traslado (Ozlack, 1983).

Asimismo el complejo metal-mecánico es desarticulado, cuando se encontraba en una fase de transición e integración con tecnologías y centros de punta, en particular con el incipiente polo informático.

Las empresas transnacionales y los grupos económicos locales más concentrados se convertirán en el polo dinámico de la acumulación, subordinando a los capitales nacionales y a las pequeñas y medianas empresas. Las actividades productivas principales se orientarán a la producción de manufacturas de origen agropecuario y a los bienes derivados de las actividades extractivas.

Este proceso tuvo lugar a través de las políticas represivas encaradas desde el estado, junto a la apertura externa de la economía y la reforma cambiaria que - mediante la drástica reducción de los salarios y el incremento de la deuda externa - facilitaron la diversificación e integración de las actividades productivas de los grupos locales y extranjeros más influyentes. Se asiste desde entonces a una creciente profundización y heterogeneización de la pobreza.

La convergencia de estos factores junto a la creciente pauperización de las clases medias, dieron lugar a la aparición y consolidación de nuevas formas de ocupación del suelo como los asentamientos. Estos se diferencian de las villas miseria, entre otras características, por el carácter planificado de su origen, una trama barrial que respeta las normas urbanas, y, por la distinta base social que los conforma (Merklen, $1991 \mathrm{y}$ posteriores).

La severa desindustrialización de la RMBA, junto a las políticas de promoción industrial a otras regiones del país parecieron configurar, durante la década de los 80 , tendencias a la desconcentración de la región, junto al desarrollo de ciudades intermedias de carácter no metropolitano.

Desde el comienzo del periodo considerado, el crecimiento vegetativo supera al migratorio, en tanto que la región pasa de tener 9.700 .000 habitantes en 1980, a casi 10,8 millones en 1990 , creciendo solo un $1 \%$ y continuando con la tendencia poblacional decreciente de la década de los 70, cuando el crecimiento demográfico fue del 
$1,6 \%$. Asimismo se constituye el AMBA (Area Metropolitana de Buenos Aires), entidad interjurisdiccional que aspiraba a coordinar el planeamiento metropolitano del territorio conformado por la Capital Federal y los entonces 19 partidos del Gran Buenos Aires.

\section{ETAPA DE INSERCIÓN GLOBAL DE LA RMBA}

La economía global induce cambios en las relaciones entre espacio y producción, que tienen como epicentro a los grandes espacios metropolitanos. Las regiones metropolitanas en América Latina, no tienen el carácter expandido que es posibilitado en otros continentes por el desarrollo de las comunicaciones y la segmentación de los procesos de trabajo. Ello se debe a las restricciones históricas derivadas del patrón de desarrollo urbano latinoamericano, concentrado en ciudades primadas y a las nuevas restricciones que impone la existencia de servicios e infraestructuras a las localizaciones industriales. (Jaramillo, 1990). Al igual que otras regiones metropolitanas de América Latina, la RMBA ha sufrido importantes procesos de reestructuración socio-económica durante la década de los 90 .

Estos procesos se vinculan directamente con las políticas de ajuste estructural que se inplementaron bajo imposición de los organismos financieros internacionales (Fondo Monetario Internacional y Banco Mundial, principalmente). Una breve caracterización de esas políticas incluye los siguientes rasgos fundamentales: por un lado, la desregulación y apertura de las economías nacionales y, por el otro, la reducción del rol del estado como agente económico y de regulación, de prestador de servicios de consumo colectivo y también en su función de compensador social de las "fallas del mercado".

Entre las consecuencias más destacables de las políticas de ajuste estructural puede distinguirse el ingreso de capitales del exterior, acompañados por un proceso creciente de concentración del capital en pocos grupos, que se van apropiando de los sectores más rentables de la economía nacional, con inversiones dirigidas casi exclusivamente a la explotación de los mercados internos, tendiendo a consolidar el mercado como institución fundamental. Los cambios producidos por las políticas antes mencionadas han repercutido en la conformación de la estructura socio-económica y, consecuentemente, en la organización territorial de la RMBA.

El impacto de la globalización en la última década, junto a la privatización y desrregulación de los servicios urba- nos públicos y las inversiones extranjeras directas, orientadas preferentemente a los sectores de infraestructuras y comunicaciones, fueron definiendo un sentido poco productivo para el conjunto de la región, de tipo enclavistico, mas asociado a las redes globales en las cuales se insertan estas inversiones y procesos productivos, que al propio contexto regional y nacional donde se ubican.

La aplicación del Plan económico de Convertibilidad, desde el año 1991, estableció la paridad cambiaria del peso argentino con el dólar estadounidense e inhibió al estado de recaudar y transferir divisas del sector agrario al industrial. La RMBA se desarrollará como resultado de tendencias socio-espaciales superpuestas, afianzándose como la zona mas urbanizada del país y en donde se concentra la mitad de su Producto Bruto Interno. Buenos Aires muestra tendencias a una organización fracturada y dual del espacio urbano que presenta, por un lado, los restos del espacio forjado por la lógica taylorista-fordista y que se caracteriza por sus condiciones de deterioro y desestructuración socioterritorial y, por otro lado, los nuevos espacios centrales y periféricos que responden a la lógica posfordista, posmoderna y posindustrial (Cicolella, 1999).

El cambio hacia un régimen de acumulación posfordista o cuasi-posfordista de tipo flexible se encuentra relacionado con las nuevas dinámicas territoriales, como así también con la creciente pérdida de control sobre los procesos económicos, sociales y territoriales que se desarrollan en la región. Las transformaciones urbanas en los últimos 15 años tienden a ser capital intensivas e independientes del tamaño de la población, de la demanda de trabajo o del consumo masivo.

En este contexto se verifica una competitividad creciente entre regiones y ciudades por la radicación de inversiones extranjeras que induce tendencias a la "remetropolitización". El 25\% de las inversiones globales que se realizaron en el país se concentraron en la Capital Federal y el Gran Buenos Aires, particularmente en los sectores de infraestructura, comercio y servicios (Russo, 1999).

En el sector de la construcción, un pequeño grupo de empresas constituyen grandes conglomerados económicos formando "holdings" y "subholdings", monopolizando las actividades de manera directa o por intermedio de formas controladas y/o vinculadas. Participan directamente en las privatizaciones, utilizando sus contactos históricos en la plaza. Reciben transferencias financieras desde el exterior, se asocian con inversores directos extranjeros, internacionalizan modalidades de gerenciamiento y de 
gestión, forman uniones corporativas para acreditar capacidades tecnológicas que les permitan participar en ciertos negocios, organizan subsidiarias, etc (Federico Sabaté, 1999).

En la RMBA unos 15 grupos o conglomerados económicos logran controlar más del 50\% del mercado inmobiliario y de la construcción. Sobre 3.000 firmas existentes en el país, el $70 \%$ se encuentran afincadas en la región, (con un $28 \%$ de desocupados en la actualidad) dando trabajo pleno a 290.000 personas asalariadas o no.

El sector "productor de la ciudad" entre 1990/98 aumentó su producto tres veces más que el PBI, estimándose su comportamiento como muy dinámico e independizado de los ciclos económicos (Federico Sabaté, 1999).

Los objetos inmobiliarios producidos, financiados y negociados que concentran la atención de este sector, abarcan torres de viviendas exclusivas y diferenciadas para capas sociales de altos ingresos (con inversiones que varían entre u\$s 100.000 y u\$s 1.000 .000 para cada emprendimiento), barrios y clubes cerrados, pueblos privados "ecológicos" que extienden el territorio metropolitano (ocho periurbanos promovidos en este momento, cada uno con capacidad entre 25/40 mil habitantes), "shoppings" y "show centers" (unos 45 en la RMBA), hiper y supermercados (alrededor de 450), estaciones de servicio expendedoras de combustible (en números redondos, 5.000, construídas en el periodo considerado, en la RMBA), obras viales diversas y su gestión y mantenimiento vinculadas a la “economía automotor", obras portuarias y estructuras industriales (35\% en la RMBA), oficinas inteligentes y reacondicionadas (sobre tres millones de $\mathrm{m}^{2}$ totales en la RMBA, $18 \%$ de los de mayor calidad en manos de una sola firma), hotelería (130.000 $\mathrm{m}^{2}$ producidos solo en la ciudad de Buenos Aires entre 1992/97), aparatos turísticos de nivel internacional (Federico Sabaté, 1999).

Las mencionadas construcciones constituyen y sostienen el tipo de integración de lugares, recortes territoriales de la RMBA concatenados al sistema global, bajo la forma de enclaves modernos intraurbanos, que utilizan altas tecnologías y que los conectan más al mundo que a su propio contexto interno o local. A su vez, en lo físico, contribuyen a la paulatina fragmentación del espacio metropolitano (Federico Sabaté, 1999). La forma espacial tentacular o de "mancha de aceite", que presentaba la región durante la etapa sustitutiva de importaciones, se redefine hacia un crecimiento metropolitano en red, de bordes difusos, policéntrica, constituyendo una megalópolis o archipiélago urbano donde se concentran los nuevos espacios de gestión, actividades financieras, comerciales y de la producción empresarial (Cicolella, 1999).

Las tendencias a la "remetropolitización", es decir al predominio económico, político y cultural de la RMBA, no ha modificado la pérdida de su importancia demográfica en relación a otros conglomerados urbanos y al conjunto del país. ${ }^{1}$

El GBA muestra a su vez, en comparación a los conglomerados urbanos restantes donde predominan las actividades de distribución, una mayor importancia de los sectores vinculados a la producción y los que incluyen flujos físicos, de personas, de información y financieros (Lindenboim, 2000). La importancia de las actividades productivas se ve corroborada por el mayor peso que, sobre el empleo de la región, poseen las actividades manufactureras, que se agrupan en los siguientes subsectores: textiles, confecciones y calzado; productos químicos y de la refinación de petróleo y combustible nuclear; los productos metálicos, maquinarias y equipos, y otras actividades manufactureras.

La importancia de las actividades vinculadas a la circulación con respecto al resto urbano se ve asimismo reflejada por el peso del empleo en los sectores de comercio al por mayor, restaurantes y hoteles, transporte, servicios conexos al transporte y las comunicaciones, intermediación financiera y las actividades inmobiliarias, empresariales y de alquiler (Lindenboim, 2000). Esta prevalencia de las actividades productivas y de circulación en la región con respecto al resto urbano tiene lugar en un contexto de apertura externa de la economía argentina que generó una fuerte mutación del proceso industrial con reducción del peso relativo de la producción manufacturera. En la RMBA se ha verificado una reducción de más de 160.000 trabajadores en el sector, comparando los dos últimos censos económicos (Borello et alii, 1999). En 1994, se encontraban ocupados en el sector 580.000 trabajadores en unos 48.000 establecimientos. El 37\% de ellos se localizaba, en 1999, en la Ciudad de Buenos Aires, única jurisdicción donde crece la ocupación de manera significativa, reafirmando la dinámica de concentración territorial y centralización de las decisiones (Federico Sabaté, 1999).

Existen distintos criterios para definir el territorio de la RMBA, según se tomen en cuenta las comunicaciones, los transportes, las infraestructuras urbanas, etc. La definición de región es una convención operativa útil para dar cuenta del proceso de regionalización en las condiciones socioespaciales actuales (Federico Sabaté, 1999). Puede utilizarse como criterio para su definición el basado en los movimientos pendulares que diariamente realizan las 
personas para satisfacer sus necesidades principalmente laborales pero también educativas, de salud y de consumo que guardan a su vez cierta correspondencia con la estructura de transporte de la región ${ }^{2}$ (Kralich, 1995).

En el interior del Conurbano Bonaerense, los partidos que centralizan los mayores índices de pobreza y carencias de infraestructuras se concentran en las zonas mas alejadas de la Ciudad de Buenos Aires. Son asimismo los partidos que poseen mayor crecimiento poblacional. Este crecimiento es atribuído, además del crecimiento vegetativo, a las migraciones provenientes desde el interior del país en busca de trabajo y a la relocalización de la población pobre al interior de la región, proveniente de la Ciudad de Buenos Aires, debido a los altos costos de los servicios y a la política de erradicación de villas miserias antes señalada.

En la RMBA se ha registrado en la última década un notable aumento de la tasa de actividad general, una mayor participación en el mercado de trabajo de las mujeres de todas las edades y un inédito aumento de la desocupación abierta que alcanza los dos dígitos, que ubican a esta región como uno de los ámbitos de más alto nivel de desocupación del país.

Las modificaciones ocurridas en el mercado de trabajo han generado una fuerte segmentación del mismo, al tiempo que han crecido, a tasas socialmente no soportables, el desempleo (15,5\% en la RMBA), la subocupación (17\% en la RMBA), la precarización (falta de estabilidad, trabajo a domicilio, extensión temporal del contrato a prueba, tercerización, contratos por prestación de servicios, y otras formas que restringen, eluden o anulan derechos de los asalariados) y la marginalidad laboral (de aquéllos que desalentados por la situación, ya no intentan siquiera buscar trabajo o no pueden enfrentar los gastos y costos de transporte para hacerlo). Paralelamente se registra un crecimiento del $10 \%$ de la sobreocupación (de las personas que logran tener más de un empleo para sobrevivir porque no alcanza el salario) y de las horas de trabajo extra no remunerado (se estima que crece en un 12\%). A ello se agrega la redistribución regresiva del ingreso personal (Altimir y Beccaria, 1998) y la secuela "natural" del aumento de la pobreza absoluta y relativa, e indigencia.

Más de un $60 \%$ de los hogares metropolitanos se encuentran debajo de la línea de pobreza (LP). Algunos analistas calculan la población excedente de la RMBA en un 52\% de la PEA (Cess, 1999), sumando a los desocupados, la población autosostenida. Para completar este cuadro es dable agregar que el crecimiento de la desocupación en el GBA fue del $261 \%$ entre $1991 / 99$, mientras que la misma variación del país fue del $210 \%$ (Clarín, 1999). En lo que hace al tercer cordón de la RMBA, el área más duramente golpeada en la comparación del sistema urbano nacional, la desocupación actual llega al 22\% (Federico Sabaté, 1999).

En los sectores del trabajo (ocupados o no) que habitan las zonas más alejadas y periféricas de la RMBA, se están agregando a estas formas típicas de la explotación otras que han sido calificadas como de "expoliación urbana y ambiental" (Kowarick, 1996), que en ocasiones vuelven muy duras su cotidianeidad y condiciones de reproducción social; incluso afectando la vida útil del trabajador, con un desgaste prematuro de sus capacidades.

Observamos que a la degradación generalizada de las condiciones laborales ya mencionadas y al aumento de la rotación del trabajo, se adicionan las penurias derivadas de la autoconstrucción desmigajada de la vivienda (más de un $65 \%$ de las existentes en la RMBA, según los expertos), las deficientes condiciones de transporte, la degradación del medioambiente que generalmente rodea o es aledaño al hábitat, la lejanía y deficiente accesibilidad a los equipamientos urbanos de recreación, salud y educación, los déficits crónicos en calidad o cantidad de los servicios referidos a la infraestructura urbana (ausencia o mala provisión de agua potable, saneamiento, recolección inadecuada de residuos sólidos domiciliarios, escaso alumbrado público, ausencia de cordón cuneta en pavimentos de baja calidad, sin pluviales, defensas elementales contra inundaciones o anegamientos, etc) (Federico Sabaté, 1999).

Tuvo lugar a su vez una consolidación de la tendencia al afincamiento suburbano en "clubes de campo" y barrios privados de familias de sectores medios y altos en zonas anteriormente consideradas pobres. Estos desarrollos se han visto favorecidos y potenciados por la ampliación del Acceso Norte, la conclusión del Acceso Oeste, la construcción de la Autopista Buenos Aires-La Plata y la rehabilitación del tren de la Costa en el borde fluvial norte. Los partidos privilegiados donde este desarrollo es más dinámico son Pilar, Escobar y Tigre en el norte. En menor proporción, Moreno, General Rodríguez y Luján en el oeste, y Cañuelas, Ezeiza y Berazategui, hacia el sur. (Cicolella, 1999).

En conclusión: se acentúa la diferencia entre la metrópolis y el resto del país en términos de concentración de actividades económicas, de problemas de polarización social y diferencias en la distribución de los ingresos, de 
radicación de inversiones extranjeras directas y de inversión pública.

\section{NOTAS}

1. Los otros conglomerados urbanos sin incluir al GBA, son los relevados por la EPH: Córdoba, Rio Gallegos, Jujuy, La Pampa, La Plata, Paraná, Salta, San Juan, San Luis, Santa Fe, Santiago del Estero y Tierra del Fuego, Comodoro Rivadavia, y Neuquén. No incluye los conglomerados Concordia, Mar del Plata y Rio Cuarto relevadas desde 1995 (Lindemboin, 2000).

2. De acuerdo con el mismo puede distinguirse lo que se considera el AMBA que comprende a la ciudad de Buenos Aires y los 24 partidos del Gran Buenos Aires (1ra y 2da coronas) que son: Alte Brown; Avellaneda; Berazategui; Esteban Echeverría; Ezeiza; Florencio Varela; Gral San Martin; Hurlingham; Ituzaingó; J.C. Paz; La Matanza; Lanús; Lomas de Zamora; Malvinas Argentinas; Merlo; Moreno; Morón; Pte Perón; Quilmes; San Fernando; San Isidro; San Miguel; Tigre; Tres de Febrero y Vicente López. El resto de la región o "tercera corona" que se ubica por fuera del AMBA pero que tiene fuertes interrelaciones con ésta, se encuentra conformada por 15 partidos: Berisso; Brandsen; Campana; Cañuelas; Ensenada; Escobar; Exaltación de la Cruz; Gral Las Heras; Gral Rodríguez; La Plata; Luján; Marcos Paz; Pilar; San Vicente y Zàrate. Entre 1993 y 1994 se dividieron tres partidos del Gran Buenos Aires: General Sarmiento, en J.C. Paz, Malvinas Argentinas y San Miguel; Morón, en Hurlingham, Ituzaingó y Morón; y Esteban Echeverría, en Ezeiza y Esteban Echeverría. Además se creó el nuevo partido de Presidente Perón que comprende parte del territorio de San Vicente, Esteban Echeverría y Florencio Varela. En conjunto el RMBA comprende un área de $16.767 \mathrm{~km}^{2}$ y una población actual aproximada de 13.861 .845 habitantes.

\section{BIBLIOGRAFÍA}

ALTIMIR, O. y BECCARIA, L. "Efectos de los cambios económicos y de las reformas sobre la pobreza urbana en la Argentina". Informes de Investigación $n^{\circ}$ 4. San Miguel, Buenos Aires, ICI-UNGS, 1998.

BORELLO, J. A. et alii. La geografía de la industria en la RMBA; un análisis de los datos de los dos últimos censos económicos 1995-1984. San Miguel, Buenos Aires, ICO-UNGS, 1999.

CARIDE, H. "La idea de Conurbano Bonaerense (1925-1947)". Documento de trabajo $n^{\circ}$ 14. San Miguel, Buenos Aires, ICO-UNGS, 1999.

CICOLELLA, P. "Globalización y dualización en la Región Metropolitana de Buenos Aires. Grandes inversiones y reestructuración socioterritorial en los años noventa". Revista Eure. Santiago de Chile, v. XXV, n.76, diciembre 1999.

CONAMBA. El Conurbano Bonaerense. Relevamiento y Análisis. Ministerio del Interior del Gobierno de la Provincia de Buenos Aires, 1995.
FEDERICO SABATÉ, A.M. "Los ejes de análisis centrales de las áreas temáticas para abordar la cuestión urbana en la Región Metropolitana de Buenos Aires" En: Propuesta colectiva de investigadores de la UNGS (Introducción). Seminario Internacional Grandes Metrópolis del Mercosur: problemas y desafíos. Santiago de Chile, noviembre 1999.

JARAMILLO, S. "El desenvolvimiento de la discusión sobre la urbanización latinoamericana: ¿hacia un nuevo paradigma de interpretación?". La investigación urbana en América Latina. Quito, Ecuador, Ed M. Unda, v.2, 1990.

KATZ, J. y KOSACOFF, B. El proceso de industrialización en la Argentina: evolución, retroceso y perspectiva. Buenos Aires, CEAL, 1989.

KOHAN, G. y FOURNIER, M. La situación social local: La inserción laboral de los hogares de 4 partidos de la Región Metropolitana de Buenos Aires. Cartilla 2. Programa de Desarrollo Local. San Miguel, Buenos Aires, ICOUNGS, 1998.

KOWARICK, L. "Expoliación urbana, luchas sociales y ciudadanía: retazos de nuestra historia reciente". Rev Estudios Sociológicos de El Colegio de México, v. XIV n.42, 1996.

KRALICH, S. "Una opción de delimitación metropolitana: Los bordes de la red de transporte. El caso de Buenos Aires”. Seminario Internacional La gestión del territorio: problemas ambientales y urbanos. Buenos Aires, Universidad Nacional de Quilmes, Bernal, 1995.

LINDENBOIM, J. (colaboración de L. Serino) Mercados de trabajo urbano en la Argentina de los 90. CEPED, Instituto de Investigaciones Económicas de la Universidad de Buenos Aires, 2000.

LOMBARDO, J.D. "Pensamiento urbanístico y desarrollo urbano en la Región Metropolitana de Buenos Aires". Informe de Investigación $n^{\circ}$ 6. San Miguel, Buenos Aires, ICO-UNGS, 1999.

MERKLEN, L.D. Asentamientos en La Matanza. Buenos Aires, Ed Catálogos, 1991.

OZLACK, O. "Los sectores populares y el derecho al espacio urbano". Rev Punto de vista. Material de la Cátedra de Sociología Urbana/FCS-UBA, 1983.

PROYECTO Impactos de la reestructuración económica, social y territorial en la Región Metropolitana de Buenos Aires de las áreas Sistemas Económicos Urbanos y, Condiciones y Modos de vida y politicas sociales en la ciudad. San Miguel, Buenos Aires, ICO-UNGS, s.d.

ROBERT, F.G. "La gran muralla: Aproximación al tema de los barrios cerrados en la Región Metropolitana de Buenos Aires". Seminario de Investigación Urbana "El nuevo milenio y lo urbano". Buenos Aires, Instituto Gino Germani de la de F.C.S de la UBA, ICO-UNGS, Instituto de Geografía de F.F y L de la UBA y Depto de C. Sociales de la UNQUI, 1998, en edición.

RUSSO, C. "Cambios en el escenario macroeconómico e inversión extranjera en la Argentina en los años 90". Seminario Internacional sobre “ Dinámicas Territoriales y Redes en la Argentina del Mercosur”. Buenos Aires, 1999, en edición.

SURIANO, J. La huelga de inquilinos de 1907. Buenos Aires, CEAL,1983.

TORRES, H. El Mapa Social de Buenos Aires (1940-1990). Ed Dirección de Investigaciones-Secretaría de Investigación y Posgrado, FADU, UBA, 1993. 